\title{
Video Capsule Endoscopy Optimal Timing in Overt Obscure Gastrointestinal Bleeding
}

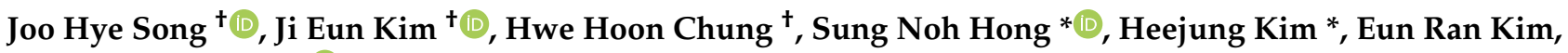 \\ Dong Kyung Chang (D) and Young-Ho Kim
}

check for

updates

Citation: Song, J.H.; Kim, J.E.; Chung, H.H.; Hong, S.N.; Kim, H.; Kim, E.R.; Chang, D.K.; Kim, Y.-H. Video Capsule Endoscopy Optimal Timing in Overt Obscure Gastrointestinal Bleeding. Diagnostics 2022, 12, 154. https://doi.org/10.3390/ diagnostics12010154

Academic Editor: Vito

Domenico Corleto

Received: 12 December 2021

Accepted: 7 January 2022

Published: 9 January 2022

Publisher's Note: MDPI stays neutral with regard to jurisdictional claims in published maps and institutional affiliations.

Copyright: (c) 2022 by the authors. Licensee MDPI, Basel, Switzerland. This article is an open access article distributed under the terms and conditions of the Creative Commons Attribution (CC BY) license (https:// creativecommons.org/licenses/by/ $4.0 /)$.

\author{
Department of Medicine, Samsung Medical Center, Sungkyunkwan University School of Medicine, \\ Seoul 06351, Korea; joohye.song@samsung.com (J.H.S.); jieun05.kim@samsung.com (J.E.K.); \\ hwehoon.chung@samsung.com (H.H.C.); erkim@samsung.com (E.R.K.); dkchang@skku.edu (D.K.C.); \\ bowelkim@gmail.com (Y.-H.K.) \\ * Correspondence: gisnhong@gmail.com (S.N.H.); heejung17.kim@samsung.com (H.K.); \\ Tel.: +82-2-3410-3409 (S.N.H.) \\ + These authors contributed equally to this work.
}

\begin{abstract}
Video capsule endoscopy (VCE) has become the noninvasive diagnostic standard in the investigation of overt obscure gastrointestinal bleeding (OGIB), with a high positive and negative predictive value. However, the diagnostic yield of the VCE is thought to depend on when it was performed. We evaluate the optimal timing performing VCE relative to overt OGIB to improve the diagnostic yield. A total 271 patients had admitted and underwent VCE for overt OGIB between 2007 and 2016 in Samsung Medical Center, Seoul, Korea. To evaluate the diagnostic yield of VCE for overt OGIB with respect to timing of the intervention, diagnostic yield was analyzed according to the times after latest bleeding. The finding of VCE was classified into P0 or P1 (no potential for bleeding or uncertain hemorrhagic potential) and P2 (high potential for bleeding, such as active bleeding, typical angiodysplasia, large ulcerations or tumors). The P2 lesion was found in 106 patients and diagnostic yield of was 39.1\% for overt OGIB. Diagnostic yield of VCE to detect P2 lesion was higher when it is performed closer to the time of latest bleeding (timing of VCE between the VCE and latest bleeding: <24 h, 43/63 (68.3\%); 1 days, 16/43 (34.9\%); 2 days, 18/52 (34.6\%); 3 days, 13/43 (30.2\%); 4 days, $7 / 28(25.0 \%) ; 5-7$ days, $6 / 24(25.0 \%)$, and $\geq 8$ days, $\left.4 / 18(22.2 \%) ; p_{\text {trend }}<0.001\right)$. The interval between the VCE and latest bleeding were categorized into $<24 \mathrm{~h}(\mathrm{n}=63), 1-2$ days $(\mathrm{n}=95), 3-7$ days $(\mathrm{n}=95)$ and $\geq 8$ days $(\mathrm{n}=18)$. Multivariable analyses showed the odds ratio for P2 lesion detection was 4.99 (95\% confidence interval, 1.47-16.89) in $<24$ h group, compared with $\geq 8$ days group $(p<0.010)$. The overall re-bleeding rate for those with P2 lesion was higher than for those with P0 or P1 lesion at the end of mean follow up of 2.5 years. The proportion of patients who underwent therapeutic intervention including surgery, endoscopic intervention and embolization was higher when VCE is performed closer to the time of latest bleeding $(p=0.010)$. Early deployment of VCE within $24 \mathrm{~h}$ of the latest GI bleeding results in a higher diagnostic yield for patients with overt OGIB and consequently resulted in a higher therapeutic intervention rate
\end{abstract}

Keywords: overt obscure gastrointestinal bleeding; video capsule endoscopy; timing of procedure; detection

\section{Introduction}

Obscure gastrointestinal bleeding (OGIB) was defined as GI bleeding of unknown etiology that persisted or recurred after negative initial evaluation using esophagogastroduodenoscopy (EGD) and colonoscopy [1]. It accounted for approximately 5\% of all cases of GI bleeding and was considered to have potential small-bowel bleeding [2-5]. On the other hands, overt GI bleeding presented with evidence of obvious bleeding, either as melena or hematochezia. Thus, overt OGIB meant that patients showed obvious GI bleeding but negative bidirectional endoscopic evaluation. 
Video capsule endoscopy (VCE) was noninvasive tool for evaluation of the entire small bowel in $79-90 \%$ of patients, with a diagnostic yield of $38 \%-83 \%$ in patients with suspected small-bowel bleeding [6-9]. Current guideline recommend VCE as a first-line diagnostic modality for potential small-bowel bleeding [10]. Previous several studies revealed that early performance of VCE in patients with overt OGIB enabled to acquire higher diagnostic yield, lead to appropriate therapeutic intervention, and better outcomes, and reduce medical cost [11-15]. However, there were some studies which showed conflicting results [16,17]. Moreover, the optimal timing of VCE application is unclear [17-21].

We investigated whether early performance of VCE provide high diagnostic yield and improve clinical outcomes in patients with overt OGIB.

\section{Materials and Methods}

\subsection{Study Population}

The VCE data performed from 1 January 2007, to 31 December 2016, at Samsung Medical Center, Seoul, Korea were eligible to this study. Inclusion criteria were as follows: (1) the indication for VCE was overt OGIB, and (2) In-hospital patients. Exclusion criteria were as follows: (1) Outpatients, (2) VCE was performed for non-gastrointestinal (GI) bleeding, (3) patients with occult OGIB, (4) incomplete electronic medical record (EMR), or (5) capsule retention. When patients underwent repeated VCE, the first VCE finding was included in the analysis. OGIB is further divided into overt OGIB, defined by a recurrent passage of visible blood (melena, or hematochezia), and occult OGIB, defined by recurrent iron-deficiency anemia and/or recurrent positive fecal occult blood test results. The Institutional Review Board of Samsung Medical Center approved this study (2018-03-088).

\subsection{VCE Procedure and Findings}

All patients signed a written informed consent before VCE. In Korea, patency capsule was unavailable, so patients did not perform patency capsule before VCE. VCE were performed using a PilCam SB ${ }^{\circledR}$ (SB1 and SB2, Given Imaging, Yogneam, Israel) or a MiroCam ${ }^{\circledR}$ (Intromedic, Seoul, Korea). Board-certificated gastroenterologists reviewed and analyzed VCE findings.

Lesions of interest identified by VCE were classified as having a potential for bleeding, or bleeding. Lesions with potential for bleeding were classified using the following three categories: P2 (active bleeding or high potential for bleeding such as angiodysplasia, ulcers, or tumors), P1 (uncertain bleeding potential such as red spots, erosions, polyps, venous ectasia, diverticulum, or submucosal tumors), and P0 (no bleeding potential such as nodules, visible submucosal veins, or diverticula without the presence of blood). A positive VCE finding was defined when P2 lesions detected by VCE could explain the patient's focus of GI bleeding.

\subsection{Outcome Measurement}

Laboratory findings including hemoglobin $(\mathrm{Hb})$, platelet count, prothrombin time [13] were measured at the time of GI bleeding. Clinical features of enrolled patients were assessed by reviewing EMR, retrospectively. We reviewed age, sex, underlying diseases (liver cirrhosis, end-stage renal disease (ESRD), and coronary artery disease), history of abdominal surgery, and use of anti-platelet drug, anti-coagulant drug, and nonsteroidal anti-inflammatory drugs (NSAIDs). In addition, we assessed timing of VCE (length time between VCE and last GI bleeding; days), transfusion requirements of pack red blood cell ( $\mathrm{pRBC})$, the number of GI bleeding episodes, days of hospitalization, treatment for overt OGIB; therapeutic intervention (surgery, endoscopy, or embolization) and conservative management (medication, or close observation), and re-bleeding rate. The timing of VCE were divided into 4 groups: $<24 \mathrm{~h}, 1-2$ days, $3-7$ days and $\geq 8$ days.

Primary outcomes were diagnostic yield of VCE and therapeutic intervention rate according to timing of VCE. Diagnostic yield of VCE was defined as the percentage of positive findings detected by VCE over the total number of VCEs performed for overt OGIB. 
Furthermore, therapeutic intervention rate was defined as the percentage of surgery, endoscopic intervention, or embolization over total number of treatments, including medication or observation. Secondary outcome was risk factor for P2 lesions detected by VCE.

\subsection{Statistical Analysis}

Continuous variables were expressed as mean \pm standard deviation or median with interquartile range, while categorical variables were presented as absolute values and percentages. Differences between continuous variables were analyzed using unpaired Student's $t$-test and Mann-Whitney $U$ test while differences between categorical variables were analyzed using $\chi^{2}$ test and Fisher exact test as appropriate. A $p$ value $<0.05$ was considered statistically significant. Multivariable logistic regression analysis was performed to identify risk factor for P2 lesion detected by VCE. All statistical analyses were performed using SPSS software version 27.0 for Windows (SPSS Inc., Chicago, IL, USA).

\section{Results}

\subsection{Baseline Characteristics of Enrolled Patients}

A total 482 sets of VCE performed for overt OGIB from 1 January 2007, to 31 December 2016, at Samsung Medical Center, Korea, Seoul. In this case, 211 patients were excluded and finally 271 patients were eligible in this study (Figure 1).

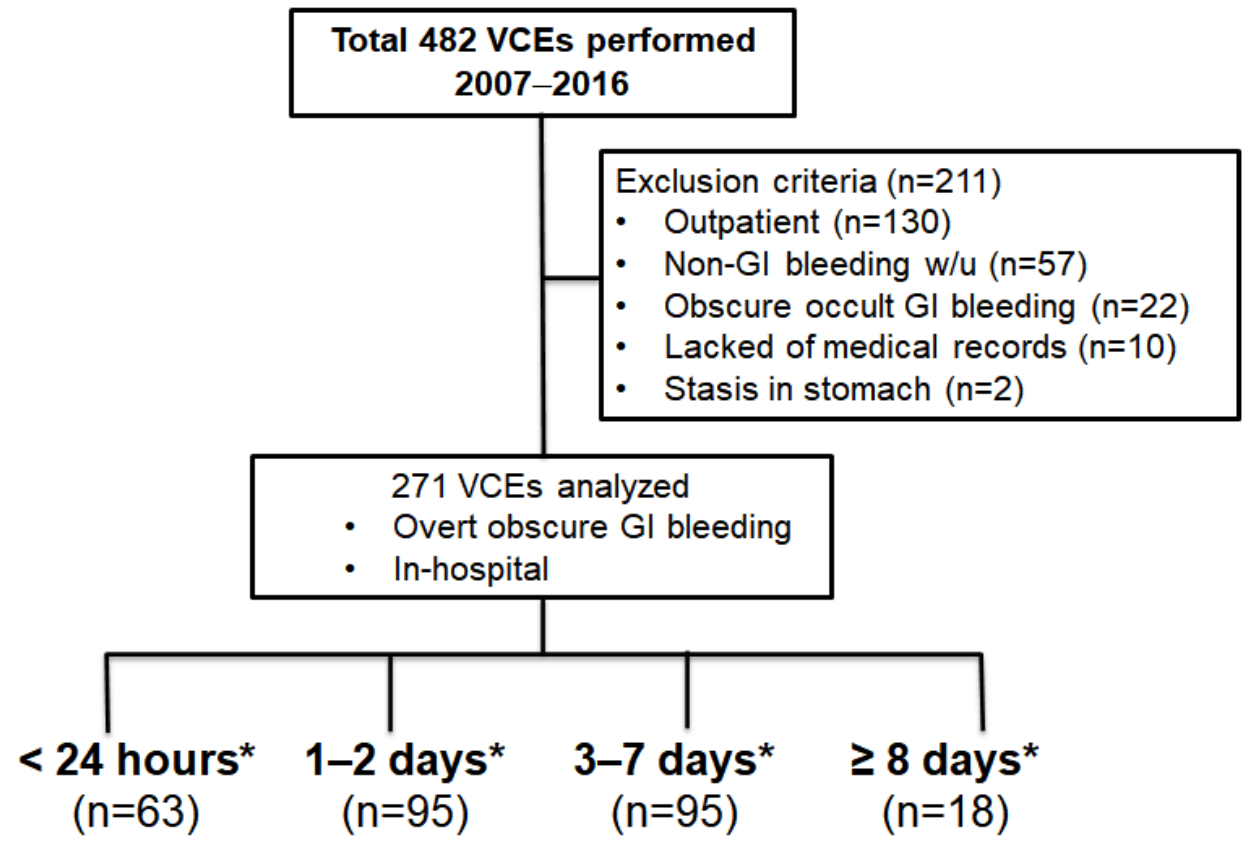

Figure 1. Study flow. ${ }^{*}$ Time interval = VCE - the latest GI bleeding; VCE, video capsule endoscopy; GI, gastrointestinal.

Comparisons of baseline characteristics of enrolled patients with P2 lesion and with P0 or P1 lesion on VCE finding are shown in Table 1. Mean age of enrolled patients was $61 \pm 15.6$ years and male were up to 65.7. PT (\%) and days of hospitalization in P2 lesion group was longer than P0 or P1 lesion group ( $p=0.039$ and 0.040 , respectively). There was no difference in usage of anti-platelet drug, anti-coagulant drug, and NSAIDs and the number of GI bleeding episodes between two groups. 
Table 1. Baseline characteristics of enrolled patients with P2 lesion and with P0 or P1 lesion on video capsule endoscopy finding.

\begin{tabular}{|c|c|c|c|c|}
\hline & $\begin{array}{c}\text { Total } \\
(n=271)\end{array}$ & $\begin{array}{l}\text { P0 or P1 Lesion } \\
(n=165)\end{array}$ & $\begin{array}{l}\text { P2 Lesion } \\
(\mathrm{n}=106)\end{array}$ & $p$ \\
\hline Age (years) & $61.5 \pm 15.6$ & $62.2 \pm 15.1$ & $60.3 \pm 16.3$ & 0.338 \\
\hline Sex, male & $178(65.7)$ & $113(68.5)$ & $65(61.3)$ & 0.240 \\
\hline Type of VCE, miroCam ${ }^{\circledR}$ & $187(68.6)$ & $112(67.9)$ & $74(69.8)$ & 0.789 \\
\hline Interval between VCE and last overt OGIB (days) & $3.0 \pm 5.7$ & $3.1 \pm 3.4$ & $2.7 \pm 8.1$ & 0.569 \\
\hline Underlying liver cirrhosis & $23(8.5)$ & $14(8.5)$ & $9(8.5)$ & 1.000 \\
\hline Underlying ESRD & $13(4.8)$ & $9(5.5)$ & $4(3.8)$ & 0.772 \\
\hline Underlying coronary artery disease & $34(12.5)$ & $19(11.5)$ & $15(14.2)$ & 0.575 \\
\hline History of abdominal surgery & $39(14.4)$ & $22(13.3)$ & $17(16.0)$ & 0.596 \\
\hline Use of antiplatelet drug & $96(35.4)$ & $57(34.5)$ & $39(36.8)$ & 0.795 \\
\hline Use of anticoagulant drug & $34(12.5)$ & $26(15.8)$ & $8(7.5)$ & 0.059 \\
\hline Use of NSAIDs & $23(8.5)$ & $13(7.9)$ & $10(9.4)$ & 0.661 \\
\hline Hemoglobin (g/dL) & $9.5 \pm 2.2$ & $9.4 \pm 2.2$ & $9.7 \pm 2.3$ & 0.334 \\
\hline Platelet (/mm3) & $202.4 \pm 90.0$ & $198.3 \pm 92.9$ & $208.6 \pm 85.4$ & 0.361 \\
\hline PT $(\%)$ & $83.9 \pm 18.3$ & $81.9 \pm 18.9$ & $86.8 \pm 17.1$ & 0.039 \\
\hline Transfusion requirement of $\mathrm{pRBC}$ & $3.2 \pm 5.6$ & $2.7 \pm 3.1$ & $4.1 \pm 8.0$ & 0.096 \\
\hline Number of GI bleeding episodes & $1.6 \pm 1.5$ & $1.6 \pm 1.7$ & $1.4 \pm 0.9$ & 0.290 \\
\hline Hospital days & $8.6 \pm 15.8$ & $6.7 \pm 6.8$ & $11.5 \pm 23.5$ & 0.040 \\
\hline
\end{tabular}

VCE, video capsule endoscopy; OGIB, obscure gastrointestinal bleeding; ESRD, end stage renal disease; NSAID, non-steroidal anti-inflammatory drug; pRBC, pack red blood cell; GI, gastrointestinal.

Baseline characteristics according to timing of VCE were shown in Table 2. Platelet was lowest on timing of $\mathrm{VCE}<24 \mathrm{~h}(187.1 \pm 67.2$ and $p=0.010)$. Transfusion requirements of pRBC was highest and hospital days was longest on timing of $\mathrm{VCE}<24 \mathrm{~h}(5.4 \pm 10.0$, $13.9 \pm 29.6$, and $p=0.007$ and $p=0.012$, respectively).

Table 2. Baseline characteristics of enrolled patients according to timing of video capsule endoscopy.

\begin{tabular}{|c|c|c|c|c|c|}
\hline & $\begin{array}{c}<24 h \\
(n=63)\end{array}$ & $\begin{array}{l}\text { 1-2 Days } \\
(\mathrm{n}=95)\end{array}$ & $\begin{array}{c}\text { 3-7 Days } \\
(\mathrm{n}=95)\end{array}$ & $\begin{array}{l}\geq 8 \text { Days } \\
(n=18)\end{array}$ & $p$ \\
\hline Age (years) & $62.7 \pm 13.5$ & $59.5 \pm 16.9$ & $62.1 \pm 14.2$ & $63.8 \pm 21.4$ & 0.488 \\
\hline Sex, male & $40(63.5)$ & $61(64.2)$ & $65(68.4)$ & $12(66.7)$ & 0.908 \\
\hline Type of VCE, miroCam ${ }^{\circledR}$ & $41(65.1)$ & $66(69.5)$ & $64(67.4)$ & $15(83.3)$ & 0.517 \\
\hline Underlying liver cirrhosis & $5(7.9)$ & $8(8.4)$ & $10(10.5)$ & $0(0.0)$ & 0.531 \\
\hline Underlying ESRD & $1(1.6)$ & $3(3.2)$ & $8(8.4)$ & $1(5.6)$ & 0.192 \\
\hline Underlying coronary artery disease & $5(7.9)$ & $9(9.5)$ & $16(16.8)$ & $4(22.2)$ & 0.160 \\
\hline History of abdominal surgery & $15(23.8)$ & $11(11.6)$ & $10(10.5)$ & $3(16.7)$ & 0.095 \\
\hline Use of antiplatelet drug & $17(27.0)$ & $29(30.5)$ & $41(43.2)$ & $9(50.0)$ & 0.068 \\
\hline Use of anticoagulant drug & $5(7.9)$ & $13(13.7)$ & $14(14.7)$ & $2(11.1)$ & 0.619 \\
\hline Use of NSAIDs & $5(7.9)$ & $9(9.5)$ & $7(7.4)$ & $2(11.1)$ & 0.928 \\
\hline Hemoglobin (g/dL) & $9.7 \pm 2.1$ & $9.8 \pm 2.2$ & $9.3 \pm 2.3$ & $9.0 \pm 2.4$ & 0.366 \\
\hline Platelet (/mm3) & $187.1 \pm 67.2$ & $199.3 \pm 106.8$ & $203.4 \pm 78.5$ & $266.6 \pm 98.4$ & 0.010 \\
\hline PT $(\%)$ & $84.5 \pm 16.1$ & $84.5 \pm 19.4$ & $82.6 \pm 20.0$ & $86.8 \pm 10.1$ & 0.816 \\
\hline Transfusion requirement of $\mathrm{pRBC}$ & $5.4 \pm 10.0$ & $2.3 \pm 2.9$ & $2.8 \pm 3.2$ & $2.9 \pm 3.1$ & 0.007 \\
\hline Number of GI bleeding episodes & $1.5 \pm 1.0$ & $1.7 \pm 2.1$ & $1.4 \pm 0.8$ & $1.4 \pm 0.9$ & 0.499 \\
\hline Hospital days & $13.9 \pm 29.6$ & $5.5 \pm 6.0$ & $8.2 \pm 8.1$ & $7.7 \pm 5.5$ & 0.012 \\
\hline Re bleeding events & $18(28.6)$ & $22(23.2)$ & $18(18.9)$ & $5(27.8)$ & 0.533 \\
\hline
\end{tabular}

VCE, video capsule endoscopy; ESRD, end stage renal disease; NSAID, non-steroidal anti-inflammatory drug pRBC, pack red blood cell; GI, gastrointestinal.

\subsection{Video Capsule Endoscopy Findings}

VCE was able to detect P2 lesions in 106 patients with $39.1 \%$ of diagnostic yield. Among P2 lesions, active bleeding was the most frequent findings ( $\mathrm{n}=48,45.3 \%)$, followed by ulcer ( $\mathrm{n}=22,20.8 \%)$, non-small bowel (SB) active bleeding but significant lesion $(\mathrm{n}=20,18.9 \%)$, and angiodysplasia $(\mathrm{n}=16,15.1 \%)$ (Figure 2$)$. 


\begin{tabular}{lc}
\hline & N (\%) \\
\hline P2 & $106(39.1)$ \\
\hline Active bleeding & $48(17.7)$ \\
Angiodysplasia & $16(5.9)$ \\
Ulcer & $22(8.1)$ \\
Non-SB active bleeding but & $20(7.4)$ \\
significant lesion & $80(29.5)$ \\
\hline P1 & $38(14.0)$ \\
\hline Erosion & $17(6.3)$ \\
Red spot & $5(1.8)$ \\
Polyp & $6(2.2)$ \\
Non-SB findings & $3(1.1)$ \\
Diverticulum & $5(1.8)$ \\
Lymphangiectasia & $3(1.1)$ \\
Phlebectasia & $2(0.7)$ \\
Submucosal tumor & $1(0.4)$ \\
\hline Petechia & $85(31.4)$ \\
\hline P0
\end{tabular}

P2 lesion

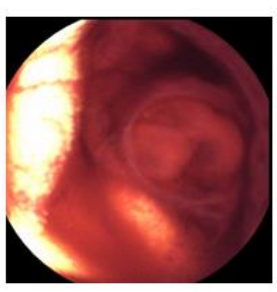

Active bleeding

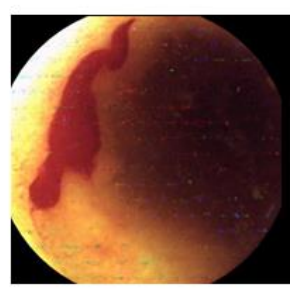

Active bleeding from angiodysplaisa

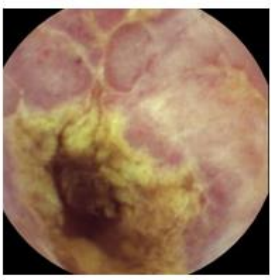

Ulcer

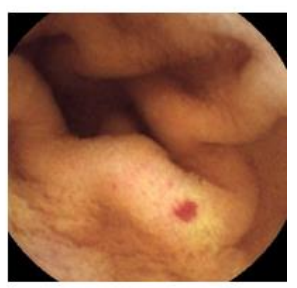

Angiodysplaisa

Figure 2. Video capsule endoscopy findings. SB, small bowel.

\subsection{Primary Outcome}

Diagnostic yield to detect P2 lesion and active bleeding according to timing of VCE were shown in Figure 3. The detection rate of P2 lesions and active bleeding were decreased significantly with timing of VCE ( $p<0.001$ for both). Therapeutic intervention rate was decreased significantly with timing of VCE $(p=0.010)$ (Table 3$)$. Therapeutic intervention rate for timing of VCE $\leq 1$ day was $39.7 \%(25 / 63)$. Therapeutic modalities for timing of $\mathrm{VCE} \leq 1$ day, were endoscopy in 21 patients, surgery in 3 patients, and embolization in 1 patient.

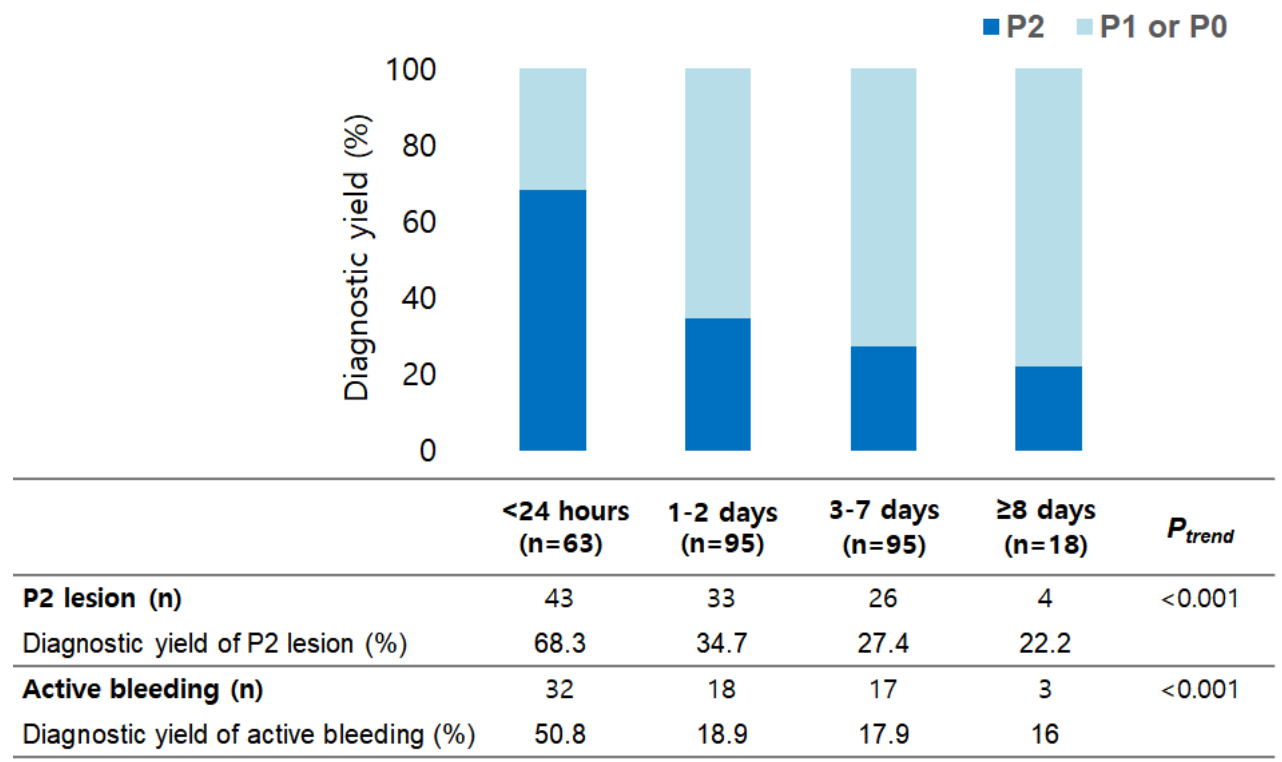

Figure 3. Diagnostic yield to detect and P2 lesion and active bleeding. 
Table 3. Management of patients with overt obscure gastrointestinal bleeding according to the duration between bleeding and video capsule endoscopy.

\begin{tabular}{cccccc}
\hline & $\begin{array}{c}<\mathbf{2 4} \mathbf{h} \\
(\mathbf{n}=\mathbf{6 3})\end{array}$ & $\begin{array}{c}\mathbf{1 - 2} \text { Days } \\
(\mathbf{n}=\mathbf{9 5})\end{array}$ & $\begin{array}{c}\text { 3-7 Days } \\
(\mathbf{n}=\mathbf{9 5})\end{array}$ & $\begin{array}{c}\geq \mathbf{8} \text { Days } \\
\mathbf{( n = 1 8 )}\end{array}$ & $p$ \\
\hline $\begin{array}{c}\text { Therapeutic } \\
\text { intervention }\end{array}$ & $25(39.7)$ & $19(20.0)$ & $20(21.1)$ & $2(11.1)$ & \\
$\begin{array}{c}\text {-Surgery } \\
\text {-Endoscopy }\end{array}$ & 3 & 4 & 7 & 0 & 0.010 \\
-Embolization & 1 & 15 & 12 & 2 & \\
$\begin{array}{c}\text { Conservative } \\
\text { management }\end{array}$ & $38(60.3)$ & $76(80.0)$ & $75(78.9)$ & $16(88.9)$ \\
-Medication & 10 & 19 & 18 & 4 \\
$\begin{array}{c}\text {-Close } \\
\text { observation }\end{array}$ & 28 & 57 & 57 & 12 & \\
\hline
\end{tabular}

\subsection{Secondary Outcome}

Risk factors for P2 lesion detected by VCE were shown in Table 4. On multivariable logistic regression analysis, timing of VCE was the risk factor for detecting P2 lesion. The odds for timing of $\mathrm{VCE}<24 \mathrm{~h}$ were 4.99 times higher, compared to timing of $\mathrm{VCE} \geq 8$ days $(95 \% \mathrm{CI}=1.47-16.89$, and $p=0.010)$.

Table 4. Risk factors for P2 detected by video capsule endoscopy.

\begin{tabular}{|c|c|c|c|c|}
\hline & \multicolumn{2}{|c|}{ Univariable Analysis } & \multicolumn{2}{|c|}{ Multivariable Analysis } \\
\hline & OR $(95 \% \mathrm{CI})$ & $p$ Value & OR $(95 \% \mathrm{CI})$ & $p$ Value \\
\hline \multicolumn{5}{|l|}{ Timing of VCE } \\
\hline$<24 \mathrm{~h}$ & $4.23(1.34-13.34)$ & 0.014 & $\begin{array}{c}4.99 \\
(1.47-16.89)\end{array}$ & 0.010 \\
\hline $1-2$ days & $1.38(0.45-4.22)$ & 0.568 & $1.63(0.51-5.23)$ & 0.414 \\
\hline 3-7 days & $1.14(0.37-3.50)$ & 0.816 & $1.24(0.39-3.94)$ & 0.720 \\
\hline$\geq 8$ days & 1 & 0.001 & 1 & 0.001 \\
\hline Age (years) & $0.99(0.98-1.01)$ & 0.337 & $0.99(0.97-1.01)$ & 0.283 \\
\hline Sex, male & $0.73(0.44-1.22)$ & 0.226 & $0.64(0.36-1.13)$ & 0.123 \\
\hline Underlying liver cirrhosis & $1.00(0.42-2.40)$ & 0.999 & $1.09(0.40-2.92)$ & 0.872 \\
\hline Underlying ESRD & $0.68(0.20-2.27)$ & 0.530 & $1.27(0.34-4.83)$ & 0.722 \\
\hline $\begin{array}{c}\text { Underlying } \\
\text { coronaryartery disease }\end{array}$ & $1.27(0.61-2.62)$ & 0.523 & $1.50(0.61-3.71)$ & 0.380 \\
\hline $\begin{array}{c}\text { History of } \\
\text { abdominalsurgery }\end{array}$ & $1.24(0.63-2.47)$ & 0.536 & $0.89(0.40-1.94)$ & 0.761 \\
\hline Use of antiplatelet drug & $1.10(0.66-1.83)$ & 0.706 & $1.27(0.63-2.58)$ & 0.506 \\
\hline Use of anticoagulant drug & $0.44(0.19-1.00)$ & 0.051 & $0.46(0.18-1.21)$ & 0.115 \\
\hline Use of NSAIDs & $1.22(0.51-2.89)$ & 0.654 & $1.01(0.39-2.60)$ & 0.991 \\
\hline $\begin{array}{l}\text { Transfusion } \\
\text { requirementof } \mathrm{pRBC}\end{array}$ & $1.05(1.00-1.11)$ & 0.076 & 1.03 (0.97-1.09) & 0.296 \\
\hline $\begin{array}{l}\text { Number of GI } \\
\text { bleedingepisodes }\end{array}$ & $0.89(0.71-1.12)$ & 0.309 & $0.88(0.68-1.13)$ & 0.319 \\
\hline
\end{tabular}

\section{Discussion}

VCE showed a diagnostic yield up to $83 \%$, but that was affected by the timing of application and the characteristics of bleeding [11,15]. Thus, patients with overt OGIB could acquire the most informative data from VCE and actually they underwent VCE first as diagnostic modality, according to current guideline [10,22]. Early deployment of VCE increased the probability to find out the source or location of GI bleeding. However, there is no consensus on exactly how early to perform VCE and high diagnostic yield of VCE lead to more therapeutic intervention and better clinical outcome. 
In our retrospective study about patients with overt OGIB who performed VCE in hospital setting, we demonstrated that the diagnostic yield of VCE for P2 lesion and especially active bleeding decreased as time of VCE was delayed. VCE performed within $24 \mathrm{~h}$ of the last overt OGIB after negative bidirectional endoscopic findings achieved a high diagnostic yield in $68.3 \%$ of patients, leading to therapeutic intervention in $39.7 \%$.

A notable increase was shown in the diagnostic yield when VCE was applied within $24 \mathrm{~h}$ of the last overt OGIB. Detection of P2 lesion and especially active bleeding by VCE declined progressively as day passed after overt OGIB. It seemed reasonable that it was consistent with the natural course of GI bleeding, which spontaneously stopped over time. On multivariable analysis, only risk factor for P2 detection by VCE was timing of VCE < 24 h (OR, 4.99; 95\% CI, 1.47-16.89, $p=0.010)$.

Early detection of bleeding focus could lead to prompt therapeutic intervention. Among therapeutic intervention modality carried out for bleeding control in our study, endoscopy was most common (endoscopy, 50; surgery, 14; embolization, 2). Endoscopic treatment was performed the most frequently in VCE within $24 \mathrm{~h}$, compared to other VCE groups ( $<24 \mathrm{~h}, 21 ; 1-2$ days, $15 ; 3-7$ days, $12 ; \geq 8$ days, 2$)$. Recent systematic review and meta-analysis study revealed therapeutic yield was higher within 2 days after bleeding for small bowel endoscopy (VCE and balloon-assisted endoscopy) and suggested that the optimal timing of endoscopy taking the therapeutic yield consideration would be within 2 days from bleeding [21]. Despite drawback of VCE that could not provide treatment directly, early localization of bleeding lesion by VCE considering its wider availability and noninvasive nature, allowed more patients with overt OGIB to receive proper treatment, especially endoscopic hemostasis, most powerful method with less invasiveness modality and more accuracy to bleeding focus.

Singh et al. and Kim et al. suggested that early performance of VCE within 3 days and 2 days each, associated with reduction of hospital days [18,19]. However, our study was not consistent with them. Our patients who performed VCE within $24 \mathrm{~h}$ were hospitalized for the longest time $(13.9 \pm 29.6$ days and $p=0.012)$ compared to other VCE groups. Our study included only patients who performed VCE in hospital setting, in contrast with Kim et al. Furthermore, in subgroup analysis, patients who underwent VCE within $24 \mathrm{~h}$ showed the highest transfusion requirement of $\operatorname{pRBC}(5.4 \pm 10.0$ and $p=0.007)$. Therefore, there was possibility that patients with more active and severe bleeding perform VCE earlier. As a result, it seemed that early deployment of VCE could not shorten hospital days in VCE $<24 \mathrm{~h}$. Nevertheless, more active and severe cases included into timing of VCE $<24 \mathrm{~h}$ group, there was no statistical difference regarding to bleeding related death among four VCE groups $(p<0.846)$. From this point of view, we might be able to infer carefully that early performance of VCE contributed to improve patient outcome.

This study had several limitations. First, it was retrospective study. Second, this study was composed of ethnic Korean individuals. Third, this study had an inherent selection bias in that all enrolled patients, especially patients who performed within $24 \mathrm{~h}$ had highrisk for active and severe bleeding (higher rate of transfusion pRBC and longer hospital days). Fourth, there are several inherent drawbacks of VCE, including a lack of therapeutic capability. In spite of this, our study revealed that high diagnostic yield and therapeutic rate by early performance of VCE. Fifth, we could not demonstrate improvement of objective indicator for clinical outcome such as hospital days.

VCE performed within $24 \mathrm{~h}$ of the last overt OGIB after a negative bidirectional endoscopic finding achieves a high diagnostic yield in $68.3 \%$ of patients, leading to therapeutic intervention in $39.7 \%$. These results indicated that VCE might play a crucial diagnostic role when performed close to the onset of overt OGIB. Performing VCE within $24 \mathrm{~h}$ could improve management of these patients by allowing for a more rapid, and appropriate therapeutic plan. 


\section{Conclusions}

VCE within $24 \mathrm{~h}$ from the last overt OGIB results in a higher diagnostic yield and higher therapeutic intervention rate. Therefore, VCE application with a $24 \mathrm{~h}$ cutoff could improve the outcome of patients. A further prospective study is warranted to confirm these findings.

Author Contributions: Conceptualization, H.K. and S.N.H.; methodology, H.K. and S.N.H.; formal analysis, J.H.S., H.H.C., H.K. and S.N.H.; data curation, H.K., H.H.C. and S.N.H.; writing-original draft preparation, J.H.S. and J.E.K.; writing-review and editing, H.K. and S.N.H.; visualization, J.H.S. and H.H.C.; supervision, E.R.K., D.K.C. and Y.-H.K. All authors have read and agreed to the published version of the manuscript.

Funding: This research received no external funding.

Institutional Review Board Statement: The study was conducted according to the guidelines of the Declaration of Helsinki and approved by the Institutional Review Board of the Samsung Medical Center (2018-03-088).

Informed Consent Statement: Patient consent was waived due to retrospective cohort study.

Data Availability Statement: The data presented in this study are available on request from the corresponding author.

Conflicts of Interest: The funders had no role in the design of the study; in the collection, analyses, or interpretation of data; in the writing of the manuscript, or in the decision to publish the results.

\section{References}

1. American Gastroenterological Association. American Gastroenterological Association medical position statement: Evaluation and management of occult and obscure gastrointestinal bleeding. Gastroenterology 2000, 118, 197-201. [CrossRef]

2. Lewis, B.S. Small intestinal bleeding. Gastroenterol. Clin. N. Am. 1994, 23, 67-91. [CrossRef]

3. Shim, K.N.; Moon, J.S.; Chang, N.K.; Hyuk, J.; Kim, J.H.; Min, B.H.; Jeon, S.R.; Kim, J.-O.; Choi, M.-G. Guideline for capsule endoscopy: Obscure gastrointestinal bleeding. Clin. Endosc. 2013, 46, 45-53. [CrossRef] [PubMed]

4. Raju, G.S.; Gerson, L.; Das, A.; Lewis, B. American Gastroenterological Association (AGA) Institute medical position statement on obscure gastrointestinal bleeding. Gastroenterology 2007, 133, 1694-1696. [CrossRef] [PubMed]

5. Pennazio, M.; Spada, C.; Eliakim, R.; Keuchel, M.; May, A.; Mulder, C.J.; Rondonotti, E.; Adler, S.N.; Albert, J.; Baltes, P.; et al. Small-bowel capsule endoscopy and device-assisted enteroscopy for diagnosis and treatment of small-bowel disorders: European Society of Gastrointestinal Endoscopy (ESGE) Clinical Guideline. Endoscopy 2015, 47, 352-376. [CrossRef]

6. Gerson, L.B.; Fidler, J.L.; Cave, D.R.; Leighton, J.A. ACG Clinical Guideline: Diagnosis and Management of Small Bowel Bleeding. Am. J. Gastroenterol. 2015, 110, 1265-1287. [CrossRef]

7. Liao, Z.; Gao, R.; Xu, C.; Li, Z.-S. Indications and detection, completion, and retention rates of small-bowel capsule endoscopy: A systematic review. Gastrointest. Endosc. 2010, 71, 280-286. [CrossRef]

8. Song, J.H.; Hong, S.N.; Chang, D.K.; Jeon, S.R.; Kim, J.-O.; Kim, J.; Lee, B.-I.; Choi, M.-G.; Kim, K.O.; Yang, D.-H.; et al. The etiology of potential small-bowel bleeding depending on patient's age and gender. United Eur. Gastroenterol. J. 2018, 6, 1169-1178. [CrossRef]

9. Rondonotti, E.; Villa, F.; Mulder, C.J.; Jacobs, M.A.; de Franchis, R. Small bowel capsule endoscopy in 2007: Indications, risks and limitations. World J. Gastroenterol. 2007, 13, 6140-6149. [CrossRef]

10. Enns, R.A.; Hookey, L.; Armstrong, D.; Bernstein, C.N.; Heitman, S.J.; Teshima, C.; Leontiadis, G.I.; Tse, F.; Sadowski, D. Clinical practice guidelines for the use of video capsule endoscopy. Gastroenterology 2017, 152, 497-514. [CrossRef]

11. Pennazio, M.; Santucci, R.; Rondonotti, E.; Abbiati, C.; Beccari, G.; Rossini, F.P.; de Franchis, R. Outcome of patients with obscure gastrointestinal bleeding after capsule endoscopy: Report of 100 consecutive cases. Gastroenterology 2004, 126, 643-653. [CrossRef]

12. Bresci, G.; Parisi, G.; Bertoni, M.; Tumino, E.; Capria, A. The role of video capsule endoscopy for evaluating obscure gastrointestinal bleeding: Usefulness of early use. J. Gastroenterol. 2005, 40, 256-259. [CrossRef]

13. Goenka, M.K. Single center experience of capsule endoscopy in patients with obscure gastrointestinal bleeding. World J. Gastroenterol. 2011, 17, 774-778. [CrossRef]

14. Leung, W.K.; Ho, S.S.M.; Suen, B.-Y.; Lai, L.H.; Yu, S.; Ng, E.K.-W.; Ng, S.S.M.; Chiu, P.; Sung, J.J.Y.; Chan, F.K.; et al. Capsule endoscopy or angiography in patients with acute overt obscure gastrointestinal bleeding: A prospective randomized study with long-term follow-up. Am. J. Gastroenterol. 2012, 107, 1370-1376. [CrossRef] [PubMed]

15. Delvaux, M.; Fassler, I.; Gay, G. Clinical usefulness of the endoscopic video capsule as the initial intestinal investigation in patients with obscure digestive bleeding: Validation of a diagnostic strategy based on the patient outcome after 12 months. Endoscopy 2004, 36, 1067-1073. [CrossRef] [PubMed] 
16. Laine, L.; Sahota, A.; Shah, A. Does capsule endoscopy improve outcomes in obscure gastrointestinal bleeding? Randomized trial versus dedicated small bowel radiography. Gastroenterology 2010, 138, 1673-1680.e1. [CrossRef] [PubMed]

17. Almeida, N.; Figueiredo, P.; Lopes, S.; Freire, P.; Lérias, C.; Gouveia, H.; Leitão, M.C. Urgent capsule endoscopy is useful in severe obscure-overt gastrointestinal bleeding. Dig. Endosc. 2009, 21, 87-92. [CrossRef]

18. Kim, S.H.; Keum, B.; Chun, H.J.; Yoo, I.K.; Lee, J.M.; Lee, J.S.; Nam, S.J.; Choi, H.S.; Kim, E.S.; Seo, Y.S.; et al. Efficacy and implications of a 48-h cutoff for video capsule endoscopy application in overt obscure gastrointestinal bleeding. Endosc. Int. Open 2015, 3, E334-E338. [CrossRef]

19. Singh, A.; Marshall, C.; Chaudhuri, B.; Okoli, C.; Foley, A.; Person, S.D.; Bhattacharya, K.; Cave, D. Timing of video capsule endoscopy relative to overt obscure GI bleeding: Implications from a retrospective study. Gastrointest. Endosc. 2013, 77, 761-766. [CrossRef]

20. Lecleire, S.; Iwanicki-Caron, I.; Di-Fiore, A.; Elie, C.; Alhameedi, R.; Ramirez, S.; Hervé, S.; Ben-Soussan, E.; Ducrotté, P.; Antonietti, M. Yield and impact of emergency capsule enteroscopy in severe obscure-overt gastrointestinal bleeding. Endoscopy 2012, 44 , 337-342. [CrossRef]

21. Uchida, G.; Nakamura, M.; Yamamura, T.; Furukawa, K.; Kawashima, H.; Honda, T.; Ishigami, M.; Fujishiro, M. Systematic review and meta-analysis of the diagnostic and therapeutic yield of small bowel endoscopy in patients with overt small bowel bleeding. Dig. Endosc. 2021, 33, 66-82. [CrossRef] [PubMed]

22. Apostolopoulos, P.; Liatsos, C.; Gralnek, I.M.; Kalantzis, C.; Giannakoulopoulou, E.; Alexandrakis, G.; Tsibouris, P.; Kalafatis, E.; Kalantzis, N. Evaluation of capsule endoscopy in active, mild-to-moderate, overt, obscure GI bleeding. Gastrointest. Endosc. 2007, 66, 1174-1181. [CrossRef] [PubMed] 